\title{
Siallorrhea in Pediatric Neurology - the Long Way from Case Series to Clinical Studies
}

F. Heinen

Bibliography

DOI $10.1055 / \mathrm{s}-0028-1119402$

Neuropediatrics 2008;

39: 195

(c) Georg Thieme Verlag KG

Stuttgart · New York

ISSN 0174-304X

Correspondence

Prof. Dr. Florian Heinen

Florian.Heinen@

med.uni-muenchen.de
The act of swallowing that we perform some 500-2000 times every day as we swallow our saliva involves a complex process of motor coordination. Because it is of such vital importance the act of swallowing is largely governed by a quite robust system of reflexes that is already well developed at birth.

Severe neurological impairment, however, can affect the ability to swallow and this can lead to various problems:

- Aspiration and aspiration pneumonia can be life threatening,

- skin macerations can become a serious problem for patient care,

- the steady fluid loss through drooling can lead to very high urine concentrations and obstipation, and last but not least

- affected patients tend to be socially isolated because most people would turn away from a drooling person.

This constitutes a whole bunch of problems on which morbidity and mortality, quality of life and participation, as well as the practice of palliative care all converge.

Only a few treatment options are available so far: Attempts to reduce the difficulties in swallowing with systemic medication have not been very successful in the long term outcome due to associated side effects. Surgical intervention is only partly successful and as such irreversible.

A more recent approach is the local injection of botulinum toxin into the salivary glands $[1,4]$. This form of treatment goes back to the $90 \mathrm{~s}$ when it was established as one of the components in the management of Parkinson's disease [2]. In pediatrics, it is good to see that single case reports are now increasingly succeeded by clinical studies [3].

This work of Bernd Wilken et al. [5] merits special thanks for investigating the clinical application of botulinum toxin for treating increased salivary flow in severe neuropediatric disorders. Using a head-to-head study design, his results make a valuable contribution to the ongoing discussions concerning the different efficacy profiles of the various commercial botulinum toxin preparations and provide an update on the questions of efficacy, safety, and the suitability of this form of therapy.

\section{References}

1 Jongerius PH, Rotteveel JJ, Hoogen F van den et al. Botulinum toxin A: a new option for treatment of drooling in children with cerebral palsy. Presentation of a case series. Eur J Pediatr 2001; 160: 509-512

2 Jost WH. Treatment of drooling in Parkinson's disease with botulinum toxin. Mov Disord 1999; 14: 1057

3 Reid SM, Johnstone BR, Westbury C et al. Randomized trial of botulinum toxin injections into the salivary glands to reduce drooling in children with neurological disorders. Dev Med Child Neurol 2008; 50: 123-128

4 Schroeder AS, Kling T, Borggaefe I et al. Long-term efficacy of intraglandular botulinum toxin injection to reduce drooling in children with neurological disorders. Dev Med Child Neurol 2008; 50 (Suppl 4): 42-80

5 Wilken B, Aslami B, Backes H. Successful treatment of drooling in children with neurological disorders with botulinum toxin A or B. Neuropediatrics 2008; 39: 200-204 